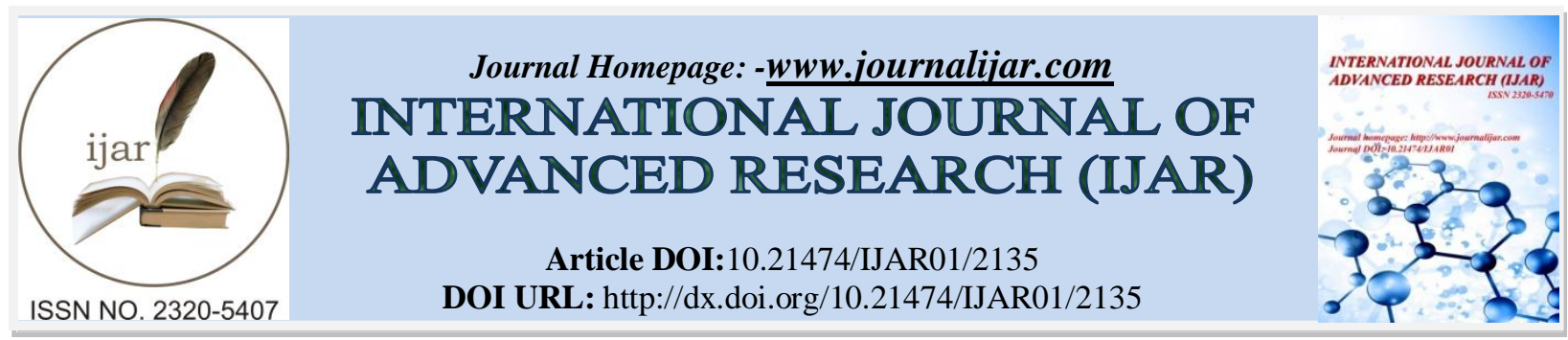

RESEARCH ARTICLE

\title{
BONE MINERAL DENSITY IN CHILDREN AND ADOLESCENTS (WITH AND WITHOUT DOWN'S SYNDROME)IN KSA: A COMPARATIVE STUDY.
}

Hatem H. Allam ${ }^{1,2}$,Lamiaa K.Elsayyad ${ }^{3}$ and AfnanM. Alkhairi ${ }^{4}$.

1. Assistant Professor, Department of Physical Therapy, College of Applied Medical Sciences, Taif University, KSA.

2. Lecturer at Faculty of Physical Therapy, Misr University for Sciences and Technology, Egypt.

3. Lecturer at Faculty of Physical Therapy, Cairo University, Egypt.

4. Bachelor of Medicine, Bachelor of Surgery, College of Medicine, Umm al-Qura University, KSA.

\section{Manuscript Info}

Manuscript History

Received: 25 September 2016

Final Accepted: 27 October 2016

Published: November 2016

Key words:-

Bone mineral density, Down's

syndrome, KSA.

\section{Abstract}

Down's syndrome (DS) is the most recognized congenital, autosomal anomaly associated with delayed physical and mental development. Adults with DS have shown decreased bone mass compared with their normal peers. Purposes of the study were to 1) compare the BMD in children and adolescents with Down's syndrome with the normal peers at Taifprovince 2) estimate the age of onset of osteoporosis and so guard against any complications.Methods: forty boys with DS assigned into GI and GII and forty normal boys assigned into GIII and GIV participated in this study. The DS subjects were trisomy 21 and selected from different special schools and institutions within Taifprovince. The age of the GI and GIII ranged from 7-10 years and for GII and GIV ranged from 14-18 years. Bone mineral density Zscore (BMD Z-score) for the whole body was measured by using BMD testing apparatus (dual X-ray absorptiometry). Age, weight, height and body mass index were matched and compared. Results:there was a significant decrease in whole body BMD-Z score in children and adolescents with DS when compared with their normal peers. In addition, there was significant decrease in GI Z- score when compared with GII. Conclusion and recommendations:the osteoporotic changes present in DSat the young age and deteriorate with aging. The acquisition of high bone mass during the childhood and adolescents is an important factor in preventing osteoporosis in later life. So, weight bearing exercises and physical activities should be promoted in children and adolescents with DS.

Copy Right, IJAR, 2016,. All rights reserved.

\section{Introduction:-}

Down's syndrome is a genetic disorder that results from achromosomal abnormality due to trisomy of all or a large partof chromosome 21. It is the most recognized congenital, autosomalanomaly associated with delayed physical and mentaldevelopment(Regezi and Sciubba, 1999). 
The musculoskeletal system of children with DS is more vulnerable (due to the incidence of hypotonia, ligamentous laxity, shortening of the upper and lower limbs, joint hypermobility and greater flexibility), and will probably need early intervention (Rogers et al., 2007). These musculoskeletal disorders of children with DS mean they may suffer from orthopedic disorders in adult life(Riquelme et al., 2006).

People with DS have a higher risk of falls and health problems. As a result, spinal trauma and femur fractures are increasingly important causes for morbidity and the incidence of fracture in those population has been reported to be high for long bones and vertebral bodies combined.(Van Allen et al., 1999)

Life expectancy in Down's syndrome (DS) population has increased over the last 70 years, rising from 9 years of age to as much as 55 years and older, and this trend is expected to continue. As the life expectancy of populations with DS increases, a reasonable prediction would show an increased incidence in osteoporosis, bone fragility and related problems (which appear mainly with age) over the coming years.Smith (2001).

Bone mineral density is a medical term referring to the amount of matter per cubic centimeter of bones. It is measured by a procedure called densitometry. The measurement is painless and non-invasive and involves minimal radiation exposure. Measurements are most commonly made over the lumbar spine and over the upper part of the hip. The forearm is scanned if either the hip or the lumbar spine can't be (Nair et al., 2007).

A bone mineral content (BMC) is a measure of the amount of minerals in a defined region of bone in grams. A real BMD is derived by dividing BMC by the area of bone measured and is expressed in grams per square centimeter (Nair et al., 2007).

High bone mass acquisition during childhood and adolescence is a key determinant for adult skeletal health. Populations with DS have shown decreased bone mass compared with subjects without intellectual disabilities (ID)(Rizzoli et al., 2010).

However, only a few of these studies have included children and adolescents with DS or specifically examined a pediatric population ,that commonly display lower values of bone mineral content (BMC) and bone mineral density (BMD) compared with peers without DS(Baptista et al., 2005).

Despite these studies, information concerning bone mass in pediatric population with DS is scarce and should therefore be given greater attention, since low bone mass (osteopenia or osteoporosis) in adulthood may be a direct result of low acquisition during growth (González et al., 2010). In Saudi Arabia, there is a relatively high incidence of Down's syndrome. The incidence has been reported as 1 in 554 live births (Niazi et al., 1995).

Much research regarding osteoporosis has been conducted in postmenopausal women and other high-risk groups, however, gaps remain in our understanding of the evaluation and treatment of osteoporosis in children with Down's syndrome. Osteoporotic problems in populations with DS are well documented in adults, however, very few studies have included children or adolescents, and even fewer have studied them specifically (Sakadamiset al., 2002).

The Z-score is the number of standard deviations above or below what is normally expected for someone of the same age, sex, weight, and ethnic or racial origin. This is helpful because it may suggest the subject has a secondary form of osteoporosis through which something other than aging is causing abnormal bone loss. (Simonelli et al., 2006).

Because a low BMD level is common among older adults, comparisons with the BMD of a typical individual whose age is matched to the examined subject can be misleading. Therefore, the diagnosis of osteoporosis or low bone mass in adults is based on the T-score and in children below 18 years is based on Z-score. (Simonelli et al., 2006).

If the score lies between (-1) to below (-2.5) this means that there is a sign of osteopenia, a condition in which bone density is below normal and may lead to osteoporosis.If the score lies above (-1), this means that, the bone density is considered normal and if itis(-2.5) or more negative, the bone density indicates osteoporosis.(Simonelli et al., 2006). 
From previously, there is a lack of information about bone mineral density in children or adolescents with DS. Since adult population with DS generally possess low bone mass, it would be of significant benefit to detect BMD in earlier ages, for example, in childhood and adolescence.

Therefore, the purposes of this study were to:1) compare the BMD in children and adolescents with Down's syndrome with the normal peers at the same age limit at Taifprovince 2) estimate the age of onset of osteoporosis and so guard against any complications that may result in the future.

\section{Subjects, Materials and Methods:-}

Subjects:-

Fortyboys with DS(GI and GII) and forty normal boys (GIII and GIV) participated in this study. Age and anthropometric characteristics illustrated in table (1). The Down's syndrome subjects were trisomy 21 and selected from different special schools and institutions within Taifprovince.They were mild mentally retarded (IQ above $60 \%$ ). They were assigned into two groups (GI, GII):

\section{The first group (GI);-}

Twenty boys with DS, their age ranged from 7 to 10 years, their height ranged from 112 to $132 \mathrm{~cm}$, their weights ranged from 18 to $31.5 \mathrm{Kg}$ and their body mass index ranged from 14.6 to 18.7 .

\section{The second group(GII);:}

Twenty boys with DS their ages ranged from 14 to 18 years,their height ranged from 140.2 to $152.4 \mathrm{~cm}$, their weights ranged from 43 to $47 \mathrm{Kg}$ andtheir body mass index ranged from 22.2 to 23.7 .

All subjects are trainable and walk freely without support. They can understand and obey orders. They are free from any other illnesses or any congenital anomalies that may affect walking, such as congenital heart disease, hearing defects, visual defects, and atlanto-axial subluxation. They had been medication-free for at least 3 months before the tests.

\section{The normal subjects: assigned into two groups:- \\ The third Group (GIII):-}

Twenty boys, their age ranged from 7 to 10 years, their height ranged from 117 to $138 \mathrm{~cm}$, their weights ranged from 16 to $29.5 \mathrm{Kg}$ and their body mass index ranged from 13.2 to 17.4 . They were selected randomly from primary schools at Taif.

\section{The fourth group(GIV):0}

Twenty boys, their ages ranged from 15 to 20 years, their height ranged from 144.2 to $157.2 \mathrm{~cm}$, their weights ranged from 41 to $45 \mathrm{Kg}$ and their body mass index ranged from 20.4 to 22.9. They were selected randomly from preparatory and secondary schools at Taif.

All parents and children were informed about the aims and procedures of the study, and benefits, and then, a letter of written informed consent was obtained from all the included subjects and their parents or guardians.

\section{Instrumentations:-}

Weight and height scalewere used to measure body weight and height.

Bonemineral density testing apparatus (dual X-ray absorptiometry)was used to measure BMD for the whole body.

The scanning method used was a narrow fan beam (45) angle with smart fan.X-ray characteristics were constant potential source at $76 \mathrm{kv}$ - dose efficient K-edge filter. According to magnification,no object planewas measured. The used dimensions were ( $\mathrm{L} \mathrm{x} \mathrm{H} \mathrm{x} \mathrm{W)} \mathrm{length} \mathrm{x}$ height $\mathrm{x}$ width263x110x128cm272 $\mathrm{kg}$ (full) and202x110x128 cm $254 \mathrm{~kg}$ (compact) 


\section{Procedures:-}

Evaluation of body mass index (BMI):

Obtain accurate height and weight measurements for each subject.The BMI was Calculatedby the following formula: weight (in kilograms) divided by the square of the height (in meters).

\section{Evaluation of BMD:-}

The BMD $\left(\mathrm{g} / \mathrm{cm}^{2}\right)$ for the whole bodywas measured for all groups and BMD Z-scores was used for comparison. This includes patients' biodata as weight, height and body mass index (BMI) and physical evaluation. Subjects were positioned on the scan table with his U.Ls held beside his body by a strap, LLs were held close to each other by a strap. All scans for the study were performed without sedation of the cases.

At first, Select a patient record from the database for a new patient and then record the necessary information of child including child data as name, birth date, heights and weight. Then using the additional tab to record fracture, indication and treatment information for the patient. Ok was selected after finishing recording the patient information, then select measure from the common toolbar, the new measurement screen was shown.

After that, all alternating materials as belts, metal buttons, and jewelers were removed from the areas of the body.The subject's body was put in a comfortable lying position in the center of the scanner table. The child's hands are flat with the palms down on the scanner table and the arms are alongside the body. Patient head is approximately $3 \mathrm{Cm}$ below the horizontal line on the table pad and straps to prevent movement during the measurements strapped the patient's knees and feet.

\section{Data analysis:-}

All statistical measures were performed through the Statistical Package for Social Studies (SPSS) version 20 for windows. MANOVA test was used to compare age and anthropometric parameters between the groups. ANOVA test was conducted to determine if there were any significant differences in the mean values of BMDZ-score between children and adolescents with and without Down's syndrome. The alpha level was set at 0.05 .

\section{Results:-}

The current study was conducted to compare the whole body BMD in children and adolescents with Down's syndrome with the normal peers at the same age limit at Taifprovince. In addition, to compare between BMD in children and adolescents with Down's syndrome to estimate the age of onset of osteoporosis, and so guard against any complications that may result in the future.

\section{Age and anthropometric parameters: Table (1):-}

The age and the anthropometric parameters were matched between GI and GIII and between GII and GIV. Statistical analysis using MANOVA showed no significant difference between GI and GIII and between GII and GIV in all measured variables at alpha level $(\mathrm{P}>0.05)$

Table 1:-Descriptive statistics and MANOVA test for age and anthropometric parameters of the selected subjects

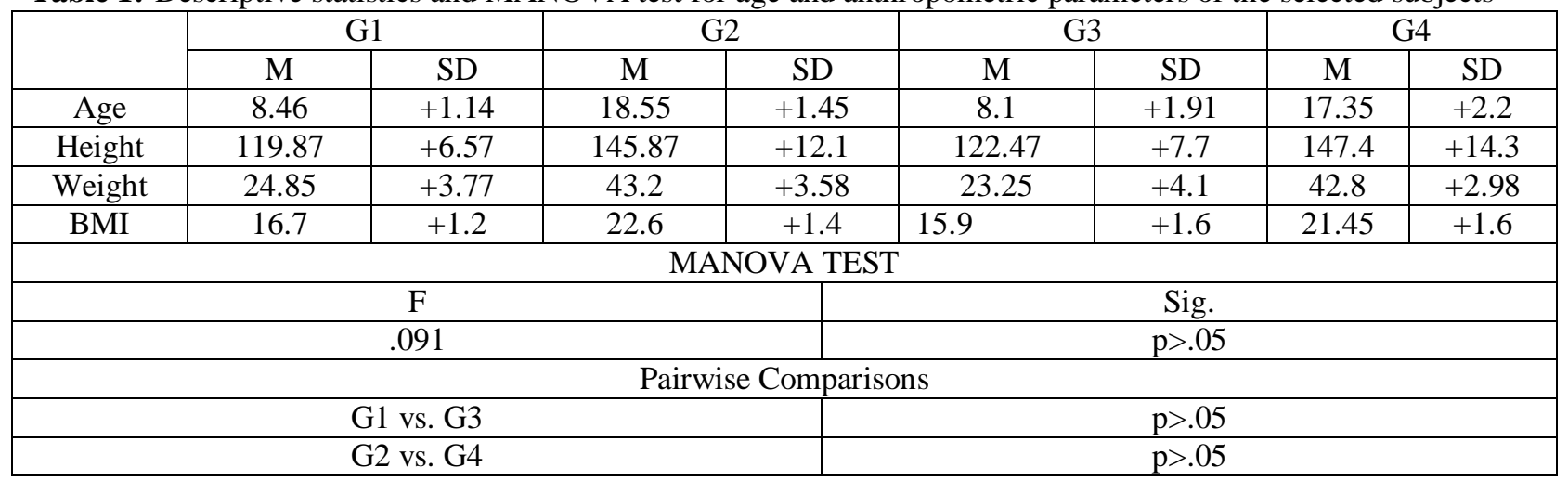

M: Mean, SD: Standard deviation, BMI: body mass index, GI: Down's syndrome children, GII: Down's syndrome adolescents, GIII: Normal children, GIV: Normal adolescents 


\section{BMD Z- scores for the whole body:-}

The mean BMD Z-score of the GI (DS children) was -1.46(+.23), so those children had osteopenia according to the meaning of the Z-score. The mean BMD Z-score of the group III (normal children) was .26(+.06). So there was a significant decrease in BMD Z-score in GIwhen compared with GIII $(\mathrm{P}>.05)$.

The mean BMD Z-score for GII (adolescents withDS)was -2.1(+0.14) which means that, those children suffering from osteoporosis according to Z-score. On the other hand, the BMD Z-score for GIV (normal adolescents) was $.8(+.3)$. So there was a significant difference between both groups in a favor of the normal group $(\mathrm{P}<.05)$.

Statistical analysis also revealed that, there was a significant decrease in BMD Z-score in GII when compared withGI $(\mathrm{P}<.05)$. Table (2).

Table 2:-Descriptive statisticsand statistical analysis for BMD Z-score of the selected subjects.

\begin{tabular}{|c|c|c|c|c|c|c|c|c|}
\hline & \multicolumn{2}{|c|}{ G1 } & \multicolumn{2}{|c|}{$\mathrm{G} 2$} & \multicolumn{2}{|c|}{$\mathrm{G} 3$} & \multicolumn{2}{|c|}{ G4 } \\
\hline & $\mathrm{M}$ & SD & $\mathrm{M}$ & SD & $\mathrm{M}$ & SD & $\mathrm{M}$ & SD \\
\hline $\begin{array}{c}\text { BMD } \\
\text { (Z score) }\end{array}$ & -1.46 & $(+.23)$ & -2.1 & $(+0.14)$ & .26 & $(+.06)$ & .8 & $(+.3)$ \\
\hline \multicolumn{9}{|c|}{ ANOVA TEST } \\
\hline \multicolumn{5}{|c|}{$\mathrm{F}$} & \multicolumn{4}{|c|}{ Sig. } \\
\hline \multirow{2}{*}{\multicolumn{3}{|c|}{2.3}} & & & \multicolumn{3}{|c|}{$\mathrm{P}<0.05$} & \\
\hline & & & \multicolumn{6}{|c|}{ Post Hoc Tests (Bonferroni) } \\
\hline \multirow{2}{*}{\multicolumn{5}{|c|}{$\frac{G 1 \text { vs. G3 }}{\text { G2 vs G4 }}$}} & \multirow{2}{*}{\multicolumn{3}{|c|}{$\begin{array}{l}\mathrm{P}<.05 \\
\mathrm{n}<05\end{array}$}} & \\
\hline \multirow{2}{*}{\multicolumn{5}{|c|}{$\frac{\mathrm{G} 2 \text { vs. G4 }}{G^{2} \text { v. }}$}} & & & & \\
\hline & & & & & \multicolumn{3}{|c|}{$p<.05$} & \\
\hline
\end{tabular}

\section{Discussion:-}

Childhood and adolescence are the most important periods to achieve the peak of bone mass. There is association between low bone mass with risk of osteoporosis and fractures(Rizzoli et al., 2010). So our study concerned with children and adolescentswithDSwho are vulnerable to reduced bone acquisition.

The results of the study revealed that, there was a significant decrease inBMD Z-score of DS children than theirnormal peers at $(\mathrm{P}<.05)$.In addition, there was significant difference between the adolescents with DSand their normal peers in BMDZ-scores in favor of normal adolescents at $(\mathrm{P}<.05)$. By comparing the BMDZ-scores of DS children with DS adolescents, there was a high significant decrease in BMDZ-scores of adolescentswith DS. (P $<05)$.

Our results came in agreement with Halaba et al., (2006)who conducted a study with ultrasonography and found lower amplitude-dependent speed of sound, which depends on BMD, in 24 children with genetic disorders (including seven children with DS) compared with age-matched children without ID, however, the difference remained stable with time indicating low bone mass

The decreased BMDmay be attributed to that, subjects with DS were described as less active and more prone to spending more time indoors, than their normal peers as reported by (Sharavand Bowman, 1992). Furthermore, Gracia-Marco et al., (2011) said that, environmental and lifestyle factors, such as physical activity (PA) have an important role in bone mass acquisition due to their osteogenic effects. PA is a key factor in disease prevention and provides several benefits in overall health and specifically in skeletal health.All these factors may contribute to decrease BMD in DS subjects.

In addition to that and according to Sayers, (2007) who mention that, persons with DS experience several barriers to participate in daily (PA) like transportation restrictions, low motivation and lack of integrated program options. Consequently, low levels of PA and physical fitness have been described in this population and so they are less active than those without disabilities.

As the mechanostat theory stated by Rauch et al.,(2004)which suggests that both systematic exercise and PA could drive to a direct osteogenic effect on bone mass and an indirect osteogenic effect by increasing muscle size and 
strength and hence the tensions generated on bones. From these points of view, the BMD may be decreased in DS subjects when compared with normal peers.

On the other hand, Baptista et al., (2005), disagree with us when theyfound no observable differences in the lumbar spine BMD of children and adolescents with DS compared with children and adolescents without DS. While in adults with DS, they observed lower BMD in lumbar spine compared with adults without DS. Which may therefore suggest that, this decreased BMD could appear after puberty, since this period may be a key moment to enhance bone mass.

Our results also may be attributed to, known secondary causes for low BMD associated with DS as dietary insufficiency (vitamin D and calcium intake) and endocrine (hypothyroidism, hyperparathyroidism, hypogonadism) and autoimmune (celiac disease) disorders which can lead to inadequate nutrition. Low sunlight exposure, and anticonvulsant use have also been associated with decreased bone mass(Hobbs et al., 2000).

Guijarro et al.,(2008) reported that some conditions commonly presented in DS, such as thyroid dysfunction, abnormalities of sexual development, and musculoskeletal abnormalities (both peripheral and respiratory muscle strength) may contribute to the development of osteoporosis, which is also supports, our results.Inaddition,Sakadamis et al., (2002), told that, the increase in hydroxyproline/creatinine ratio in DS individuals is a factor possibly related to low bone mass in these patients.

Many authors as Crepaldi et al., (2007)agree that, there is a relationship between muscle strength and bone mass. They identified a correlationbetween the quadriceps strength and BMD in individuals with DS. Also Nordstrom et al., (1996) found that, the muscle hypotonia and decreased lower limb muscle strength associated with DS could affect the bone tissues.

Harris (1992) stated that children with DSsuffering from excessive hypermobility, hypotonia, which means that, the muscular control and power are significantly, reduced leading to insufficient motor action, which may negatively affect BMD.On the other hand, Sepulveda et al., (1995), disagree with us when he did not find differences in arm or leg BMD between DS and intellectually average adults.

When we compare the BMDZ-score in adolescents and children with Down syndrome, we found that there was a significant difference between both groups in a favor of the youngergroup. This come in agreement with Fatima et al., (2005) when they told that, there was a significant decreasein lumbar spine vBMD in adolescents with DS.

A paternal overprotection in adolescents with DS might be influencing and could partially explain these results as reported by (Sharav and Bowman, 1992).This fact might be also explained in part due to the general trend of decreasing PA with age in individuals with DS as mentioned byEsposit et al., (2012).

\section{Conclusion and Recommendations:-}

From previous discussion and the results of this study, and according to the reports of the investigators in the fields related to the present study, it can be concluded that, there is a significant decrease in whole body BMD-Zscore in children and adolescents with DS when compared with their normal peers. Also the BMD decreased with age.

The acquisitioning of high bone mass during the childhood and adolescents is an important factor in preventing osteoporosis in later life.So, weight bearing exercises and physical activities should be promoted in children and adolescents with DS even in mild forms. This is to guard against diseases associated with inactivity as osteoporosis, obesity, arterial diseases in adolescents and adulthood.

\section{References:-}

1. Baptista F, Varela A, Sardinha LB (2005):Bone mineral mass in males and females with and without Down syndrome. OsteoporosInt 16:380-388.

2. Crepaldi, G., Romanato, G.,Tonin, P., \& Maggi, S. (2007): Osteoporosis and body composition. Journal of Endocrinological Investigation, 30, 42-47.

3. Esposito PE, Macdonald M, Hornyak JE, Ulrich DA (2012): Physical activity patterns of youth with down syndrome. Intellect DevDisabil., 50 (2): 109-119. 
4. González-Agüero A, Vicente-Rodriguez G, Moreno LA, Guerra-Balic M, Ara I, Casajus JA (2010): Healthrelated physical fitness in children and adolescents with Down syndrome and response to training. Scand J Med Sci Sports 20:716-724.

5. Gracia-Marco L, Moreno LA, Ortega FB, Leon F, Sioen I, Kafatos A, Martinez-Gomez D, Widhalm K, Castillo MJ, Vicente-Rodriguez G (2011): Levels of physical activity that predict optimal bone mass in adolescents: the HELENA study. Am J Prev Med., 40 (6): 599-607.

6. Guijarro, M., Valero, C., Paule, B., Gonzalez-Macias, J., \&Riancho, J. A. (2008): Bone mass in young adults with Down syndrome. Journal of Intellectual Disability Research, 52, 182-189.

7. Halaba Z, Pyrkosz A, AdamczykP,Drozdzowska B, Pluskiewicz W (2006): Longitudinal changes in ultrasound measurements: a parallel study in subjects with genetic disorders and healthy controls. Ultrasound Med Biol: 32: 409-413.

8. Harris, Susan R(1988): Effects of Neurodevelopmental Therapy on Improving Motor Performance in Down's Syndrome Infants. Doctoral dissertation, University of Washingrn.

9. Hobbs, Stephanie L Sherman, Ping Yi, Sarah E Hopkins, Claudine P Torfs, R Jean Hine, Marta Pogribna, Rima Rozen, and S Jill James (2000): Maternal Risk Factors for Down's Syndrome,67:623-630, .

10. Nair AP, Jijina F, Ghosh K, Madkaikar M, Shrikhande M, Nema M. (2007): osteoporosis in young hemophiliacs from western india.am $\mathrm{j}$ hematol, 82(6):453-7

11. Niazi, M.A., al-Mazyad, A.S., al-Husain, M.A., al-Mofada, S.M., al- Zamil, F.A., Khashoggi, T.Y., al-Eissa, Y.A., (1995): Down's syndrome in Saudi Arabia: incidence and cytogenetics. Hum. Hered. 45 (2), 65-69.)

12. Nordstrom, P., Nordstrom, G., Thorsen, K., \&Lorentzon, R. (1996): Local bone mineral density, muscle strength, and exercise in adolescent boys: A comparative study of two groups with different muscle strength and exercise levels. Calcified Tissue International, 58, 402-408.

13. Rauch F, Bailey DA, Baxter-Jones A, Mirwald R, Faulkner R(2004): The 'muscle-bone unit' during the pubertal growth spurt. Bone. 34 (5): 771-775.

14. Regezi, J.A., Sciubba, J.J., (1999): Oral Pathology: Clinical PathologicCorrelations, third ed. Saunders, Philadelphia.

15. Riquelme I, Mazanal B. (2006): Desarrollo motor delniño con síndrome de Down y patologíaosteoarticularasociada. SD RevistaMédicaInternacionalsobre el Síndrome de Down, 10:34-41.

16. Rizzoli R, Bianchi ML, Garabedian M, McKay HA, Moreno LA (2010): Maximizing bone mineral mass gain during growth for the prevention of fractures in the adolescents and the elderly. Bone 46:294-305

17. Rizzoli R, Bianchi ML, Garabedian M, McKay HA, Moreno LA. (2010): Maximizing bone mineral mass gain during growth for the prevention of fractures in the adolescents and the elderly. Bone 46: 294-305.

18. Rogers PT, Coleman M, Buckley S. (2007): Atenciónmédicaen el síndrome de Down: unplanteamiento de medicinapreventiva. Barcelona: FundaciónCatalana para el Síndrome de Down; 1994. RevistaSíndrome de Down.; 20:55-9.

19. Sakadamis A, Angelopoulou N, Matziari C, Papameletiou V, Souftas V (2002): Bone mass, gonadal function and biochemicalassessment in young men with trisomy 21. Eur J ObstetGynecolReprodBiol 100:208-212.

20. Sakadamis A, Angelopoulou N, Matziari C, Papameletiou V, Souftas V (2002): Bone mass, gonadal function and biochemical assessment in young men with trisomy 21. Eur J ObstetGynecolReprodBiol 100:208-212.

21. Sayers MenearK (2007): Parents' perceptions of health and physical activity needs of children with down syndrome. Downs Syndr Res Pract. 12 (1): 60-68.

22. Sepulveda D, Allison DB, Gomez JE, Kreibich K, Brown RA, Pierson Jr. RN, Heymsfield SB (1995): Low spinal and pelvic bone mineral density among individuals with Down syndrome. Am J Ment Retard 100:109114.

23. Sharav T, Bowman T. (1992):Dietary practices, physical activity, and body-mass index in a selected population of Down syndrome children and their siblings. ClinPediatr (Philadelphia) 31:341-344.

24. Simonelli, C et al. (2006): "ICSI Health Care Guideline: Diagnosis and Treatment of Osteoporosis, 5th edition, Institute for Clinical Systems Improvement. July 37:32-35.

25. Smith DS (2001): Health care management of adults with Down syndrome. Am Fam Physician 64:1031-1038.

26. Van Allen MI, Fung J, Jurenka SB (1999): Health care concerns and guidelines for adults with Down syndrome. Am J Med Genet.89:100-110. [PubMed]. 